Research Article

\title{
ENVIRONMENTAL NOISE TRACKING SYSTEM BASED ON WEB OF THINGS
}

\begin{abstract}
Müsemma ALTINDAŞ ${ }^{1}$, Levent GÖKREM ${ }^{2} *$
Environmental noise is a collection of unwanted, disturbing or healththreatening sounds. As in the whole world, noise pollution is one of the common types of pollution that affect public health and comfort in different forms in our country. The level of noise in an environment affects human health negatively in terms of physical, psychological, physiological and performance. In this system, based on the environment we work on, web objects based environmental noise monitoring system is aimed to be made. In this study, an environmental noise monitoring network has been established which enables monitoring of indoor areas throughout the day by using sound sensor so that this system can be accessed from any environment where internet is available. As a result, remote environmental noise monitoring is provided in real time. In this study, the objective of the noise monitoring network as a sub-based web object is a project which is intended to control the problems arising from the public health, labor force, industrialization and the development of modern life. As a result of the researches and observations, it is recommended to present them to the field in order to provide awareness and sensitivity to environmental noise pollution. The measuring accuracy of the system was tested with the HT-80A noise meter.
\end{abstract}

Key words: Noise, Internet of Things, Web of Things, Tracking System

\section{Introduction}

Noise has been recognized as an environmental problem arising from industrialization and the development of modern life, negatively affecting people's hearing and perception, which can disrupt psychological, physical and physiological balance and reduce their ability to work. Noise measurement is done with the sonometer, it is a stringed instrument that measures the intensity of sound. The sonometer gives the intensity of the sound in a decibel type. The decibel $(\mathrm{dB})$ is the unit of sound intensity and is a logarithmic unit used to measure the volume and express the ratio of the physical two values. The decibel value varies logarithmically according to sound intensity. The decibel is associated with the 10-based logarithm. " 1 " bel is " 10 " decibels. $20 \mathrm{~dB}$ is " 10 " times more severe than $10 \mathrm{~dB}, 30 \mathrm{~dB}$ is " 100 " times more severe than $10 \mathrm{~dB}$ because of the calculation of the decibel at the base of the $\log 10$. " 0 " decibels is measured as the operating starting level of the human ear and $140 \mathrm{~dB}$ as the sound produced by the jet engine (Table 1).

\footnotetext{
${ }^{1}$ Department of Mechatronics Engineering, University of Tokat Gaziosmanpaşa, Tokat, TR, (musemmaaltindas@ gmail.com) (D) https://orcid.org/ 0000-0001-7536-1079

2 Department of Mechatronics Engineering, University of Tokat Gaziosmanpaşa, Tokat, TR, (levent.gokrem@ gop.edu.tr) (Dhttps://orcid.org/ 0000-0003-2101-5378
} 
Table1. dB Ratings and subjective evaluations of some types of noise [1]

\begin{tabular}{|c|c|c|}
\hline \begin{tabular}{c|} 
Noise \\
Level (dB)
\end{tabular} & Examples & Subjective Assessment \\
\hline 140 & Close to the Jet engine & \multirow{3}{*}{ Damaging } \\
\hline 130 & Onset of pain & \\
\hline 105 & Powerful rock music & \\
\hline 100 & Car klaxon sound $3 \mathrm{~m}$ away & \multirow{3}{*}{ Sky-High } \\
\hline 90 & City street noise & \\
\hline 82 & Factory noise & \\
\hline 80 & School without acoustic insulation, canteen noise & \multirow{2}{*}{ High } \\
\hline 62 & Open traffic road & \\
\hline 62 & The noise of a secondary road & \multirow{2}{*}{ Middle } \\
\hline 50 & Clerical noise & \\
\hline 40 & Music played at a low level in the residence & Low \\
\hline 20 & Whisper & \multirow{3}{*}{ Very Low } \\
\hline 8 & Human breathing & \\
\hline 0 & Beginning of hearing & \\
\hline
\end{tabular}

The effect of noise pollution on human health also varies according to sound intensity and length of noise duration. For example, the human ear can withstand $85 \mathrm{~dB}$ of noise without damage for 8 hours, but this violence over $94 \mathrm{~dB}$ of noise, this time is reduced to 1 hour. 55-65 dB noise causing psychological disturbance, $65-90 \mathrm{~dB}$ noise disturbing the peace, 90 and above are described as noise causing physiological disorder [1]. A classification of the effects of noise has been made in Table 2 .

Table 2. A classification of the effects of noise

\begin{tabular}{|l|l|}
\hline $\begin{array}{l}\text { I. Noise in Degrees } \\
55-65 \mathrm{~dB}\end{array}$ & Slight, Feeling bored, Anger, Concentration, Sleep disorder \\
\hline $\begin{array}{l}\text { II. Noise in Degrees } \\
65-90 \mathrm{~dB}\end{array}$ & $\begin{array}{l}\text { Physiological noise, Heartbeat change, } \\
\text { Respiratory acceleration, Decreased brain pressure }\end{array}$ \\
\hline $\begin{array}{l}\text { III. Noise in Degrees } \\
90-120 \mathrm{~dB}\end{array}$ & Physiological noise, Headache \\
\hline $\begin{array}{l}\text { IV. Noise in Degrees } \\
120-140 \mathrm{~dB}\end{array}$ & Disorder of the inner ear \\
\hline $\begin{array}{l}\text { V. Noise in Degrees } \\
140>\mathrm{dB}\end{array}$ & The eardrum burst \\
\hline
\end{tabular}

Noise is a factor affecting life. It is known that those exposed to noise above $140 \mathrm{~dB}$ have hearing problems and go up to the eruption of the eardrum. Therefore, noise measurements are extremely important. Purpose of noise measurements are made with the aim of assessing complaints, checking compliance with the law, determining the number of exposures, calibration accuracy, Environmental Impact Assessment (EIA) noise mapping. External factors and related factors affecting noise measurement should be considered during the measurement. The first study before noise measurement 
is that a planning should be made on how often, when and for what purpose the noise should be evaluated [2]. An accurate planning will ensure that the correct noise measurement results are received. Noise measurement should be carried out in accordance with the 'Environmental Noise Assessment and Management Regulation' [3]. Measurements of the sound pressure are performed with noise measuring devices and are used for continuous monitoring of the noise level. With portable noise measuring devices, it can quickly and easily control noise intensity and perform regular measurements with these devices. But today systems face ease of remote access due to the frequent use of internet protocol therefore, remote data operation has started to be preferred. With remote access, it can be controlled with any device from anywhere with internet access and can be instantly informed of the environment measured by the scenarios created [4]. These systems are called web-based systems. Today, industrial automation systems, greenhouse automation, smart (home) automation and smart devices over the internet tracking systems have been developed. It is possible to examine and follow audit systems at cheap costs using improved software. This can be accomplished with micro-controller and communication modules at a cheap cost.

In this study, a web-based decibel tracking system was developed. With this work developed, a device with internet connection can be accessed from any place at any time via web interface. We can monitor and record the ADC (Analog to Digital Converter) values and decibel values obtained from the sensor we use in our developed noise measurement device under control by providing remote access and these application are made according to the noise values determined by the Ministry of Environment and Urbanization.

\section{Materyal}

Internet of Things (IoT) is the communication network that allows us to control the physical events in our environment and to analyze with monitoring them, which is covering with software, access services and devices [5]. IoT was first used in a presentation prepared for a company by Kevin Ashton in 1999. Nowadays, the number of systems that provide remote access and control over the internet is increasing. This is accomplished by the concept of IoT. The control systems developed with micro controller and communication modules provide the opportunity to examine and follow systems at low costs using the developed software [6].

Web-based systems are IoT-supported systems. Communication modules are used to connect the microcontroller to the internet network. With the microcontroller, it can enter the web interface like a web browser, save data and keep the resulting values under control [7-10].

In the developed web-based system, all operations are performed on the designed server hard ware. In the hardware part, the sound sensor is used. Instant decibel tracking is done with sound sensor and control cards. While the decibel tracking system is made, sensor values can be monitored by connecting to the web interface programmed into the flash memory of communication module and micro controller hardware from the desired location with a device with internet connection.

Firsly the circuit to be make up the connection between the sound sensor and the microcontroller must be established and make sure that ADC values are taken from the sensor correctly. In the example circuit, Arduino as microcontroller and a Grove sound sensor as sound sensors are used. ADC values taken from the sound sensor should be converted to decibels according to the noise level of the environment. This method is described in obtaining noise data in 3. The resulting decibel values should be algorithmically programmed in accordance with the noise degrees specified in Table 2 and the data sharing should be adjusted as a result of these degrees. The resulting decibel values are connected to the 
modem via the WiFi module that is connected to the microcontroller. Here the wifi module transmits the decibel values obtained by the microcontroller to the modem. As Wifi module, the Arduinocompatible ESP8266 module is used. This module transmits data to the modem to which it is connected. However, data sent to the modem will not be immediately available for sharing. One of the ports determined by the IP address of the modem is opened to the access of external connections by performing Port forwarding. So, data is transferred to the purchased web server site on the opened port and made available to clients in the web interface. The following diagram of the system and the technical features of the circuit elements and brief information about the working structures are given.

\subsection{Microcontroller (Arduino)}

Arduino is an I/O card, a versatile Developer Hardware card that includes Processing / Wiring language applications. It has one Atmel AVR microcontroller and side equipment for other circuit elements. It has a $5 \mathrm{~V}$ regulated integrated circuit and a $16 \mathrm{MHz}$ crystal oscillator. In addition, the circuit elements in the Arduino's model according to their varies. For example, the Arduino Uno card has ATMega328 microcontroller, 14 digital I/O pins, 6 PWM outputs, 6 ADC inputs and $32 \mathrm{~KB}$ flash memory [11].

\subsection{Sound Sensor}

The Grove sound sensor was made to detect the intensity of the surrounding noise (Fig. 1). LM2904 amplifier integration and it has a microphone. It filters the high-frequency signal from the microphone with amps, enabling Arduino's signal reception. There is also a manual potentiometer on it which provides output gain. Wide voltage range, internal signal filtering, item Min. typical Max. The unit has features such as voltage 3.5 5.0 10 VDC, operating frequency $50-20,000 \mathrm{~Hz}$, sensitivity -48 $66 \mathrm{~dB}$, signal-to-noise ratio> $58 \mathrm{~dB}$, output signal range digital signal (0-1023) [12].

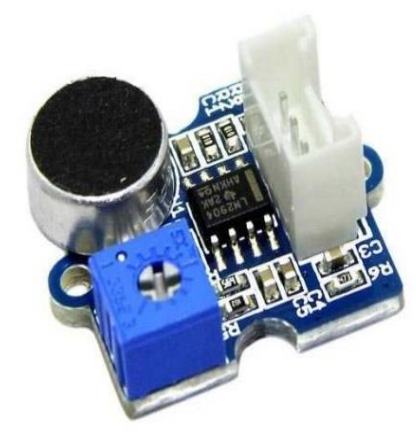

Figure 1. Grove sound sensor and cable connection table

\subsection{WiFi Module (ESP8266)}

Fig. 2 shows Esp8266 Wi-fi module and cable connection. This module can both connect to wireless networks and create a wireless network access point. In this project, it should be used to connect to the wireless network as needed. It is quite economical and useful. Supports TCP / IP protocol. Technical features; $802.11 \mathrm{~b} / \mathrm{g} / \mathrm{n}$ support, Wi-Fi direct (P2P) support internal TCP/IP protocol stack, 
$+19,5 \mathrm{dBm}$ output power (802.11 b mode) leakage current $<10 \mathrm{uA}$, low power consumption with internal 32-bit processor, STUDIO 1.1/2.0, SPI and UART support STBC, 1x1 MIMO, MIMO 2x1, waking up and receiving the data packet the time of $<2 \mathrm{~ms}$, stand-by power consumption: $<1 \mathrm{~mW}[13]$.

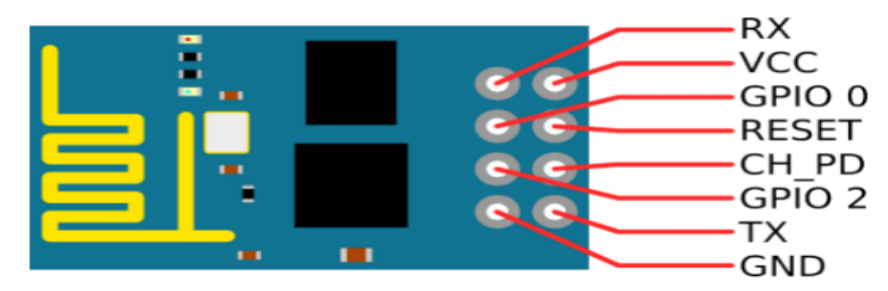

Figure 2. Esp8266 Wi-fi module and cable connection

The noise is measured by the sound sensor and transmitted to the microcontroller. The microcontroller then converts the ADC values from the sound sensor to decibels and transmits them to the modem via the Wi-fi module. The data is transferred to the web server site through the port routing process performed on the modem. This process is summarized in the following diagram (Fig. 3).

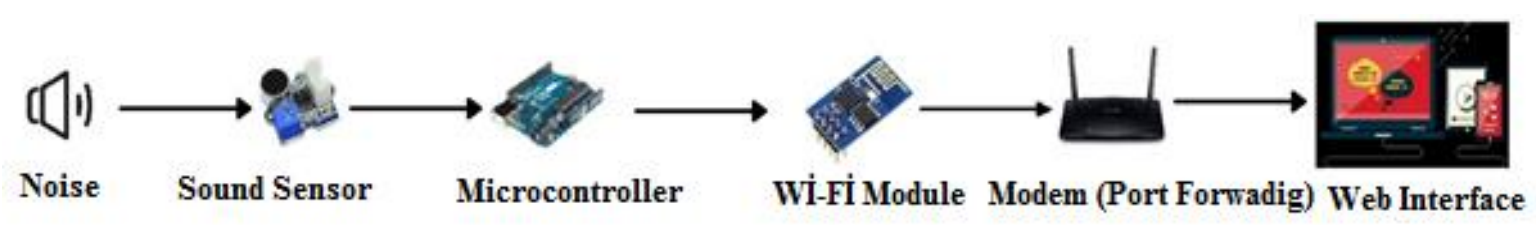

Figure 3. Circuit elements process order

\section{Method}

Noise values are measured in analog with improved software and sound sensor. ADC (Analog to digital converter) values obtained by the sound sensor must be converted to Decibel values by the formula in the logarithmic base. For this reason, the ADC values obtained with the sound sensor must be calculated using the formula with the actual decibel values and reduce the error share by keeping the error sampling number high. As a result, the decibel value corresponding to each ADC value will be created in a healthy way.

In order to move in this logic, a logarithmic function and graph are created based on the noise data and decibel values are obtained. Therefore, regression analysis is performed to create the noise function. Regression analysis is a statistical analysis used to quantify the relationship between a criterion variable and one or more prediction variables. It mainly aims to determine the property of the relationship between variables and is used to predict results using data that has a cause-and-effect relationship between them. However, the noise function is certain and due to keeping the sampling number high it is able to minimize the share of error and obtain decibel values.

$$
L_{F}=\ln \left(\frac{F}{F_{0}}\right) N_{p}=10 \log _{10}\left(\frac{F^{2}}{F_{o}^{2}}\right) d B=20 \log _{10}\left(\frac{F}{F_{o}}\right) d B
$$




$$
G_{d B}=20 \log \left(\frac{V}{V_{0}}\right) d B
$$

In the Formula (1) given above, $L_{F}$ represents the area decibel ratio, $F$ represents the measured area and $F_{0}$ represents the reference area. In Formula (2), $G$ is the power gain of decibels in electrical circuits. $\mathrm{V}$ measured voltage, $\mathrm{V}_{0}$ is also the reference voltage. But since our $\mathrm{V} / \mathrm{V}_{0}$ is set by the sensor and given to us as ADC output, the value is between 0-1023. These values are in the range of positive values, so our chart is as in the following image $[14,16]$.

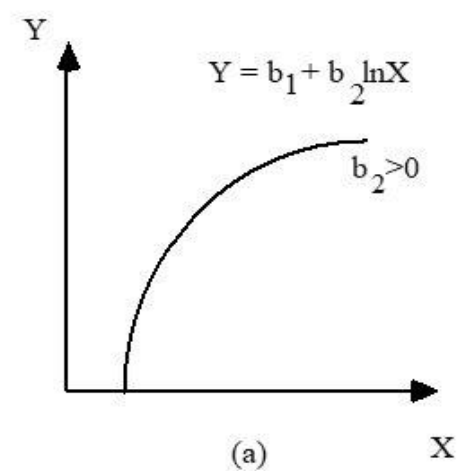

Figure 4. Logarithmic function graph of applied regression method

Fig. 4 shows logarithmic function graph of applied regression method. In this regression method;

$$
Y=b_{1}+b_{2} \ln X+u
$$

It is a model that includes dependent and independent variable in the form. Here; $Y$ is the dependent (result) variable and is considered to have a certain error. $X$ is independent (reason) variable and is thought to be measured without error. ' $\mathrm{b}_{1}$ ' is constant and is the value where $\mathrm{Y}$ is equal when $\mathrm{X}=0$. ' $\mathrm{b}_{2}$ ' is the regression coefficient and shows the amount of change in its own unit in $\mathrm{Y}$ with 1 unit change in its own unit within $X$. ' $u$ ' is the random error value and the average is zero. The variance is thought to show normal distribution. This assumption is necessary for checks of coefficients [14-15].

An important point to be mentioned above is that the ADC value varies from 0 to 1023 . That is, because $0 \mathrm{~dB}$ equals $0 \mathrm{ADC}, \mathrm{b}_{1}$ will not have any effect on the function at first. As a result of these calculations and applications, the noise function used in the micro controller software was obtained by calculating the decibel values corresponding to the sampled ADC values under the heading of regression calculation in Microsoft Office Excel.

\section{System Architecture}

While the system designed for this study measures decibel values, an interface is needed that can obtain historical data of momentarily seen and measured values. Some basic components are required for this. These components are web interface, server and modem. 


\subsection{Design of The Web Interface}

Web design is an important factor that reveals the visual status of the interface to be designed. There are many design programs that can work in accordance with NET-based software systems. By designing the desired template, the desired logo through such programs, it can produce the objects according to their type and put them together on the index cursor. Css, image, script, theme, style files created with design programs such as index.it must be merged into a web file with an html extension. It is possible to modify the contents of the integrated index file with various pad++ extension programs. Fig. 5 shows Web interface design home page.

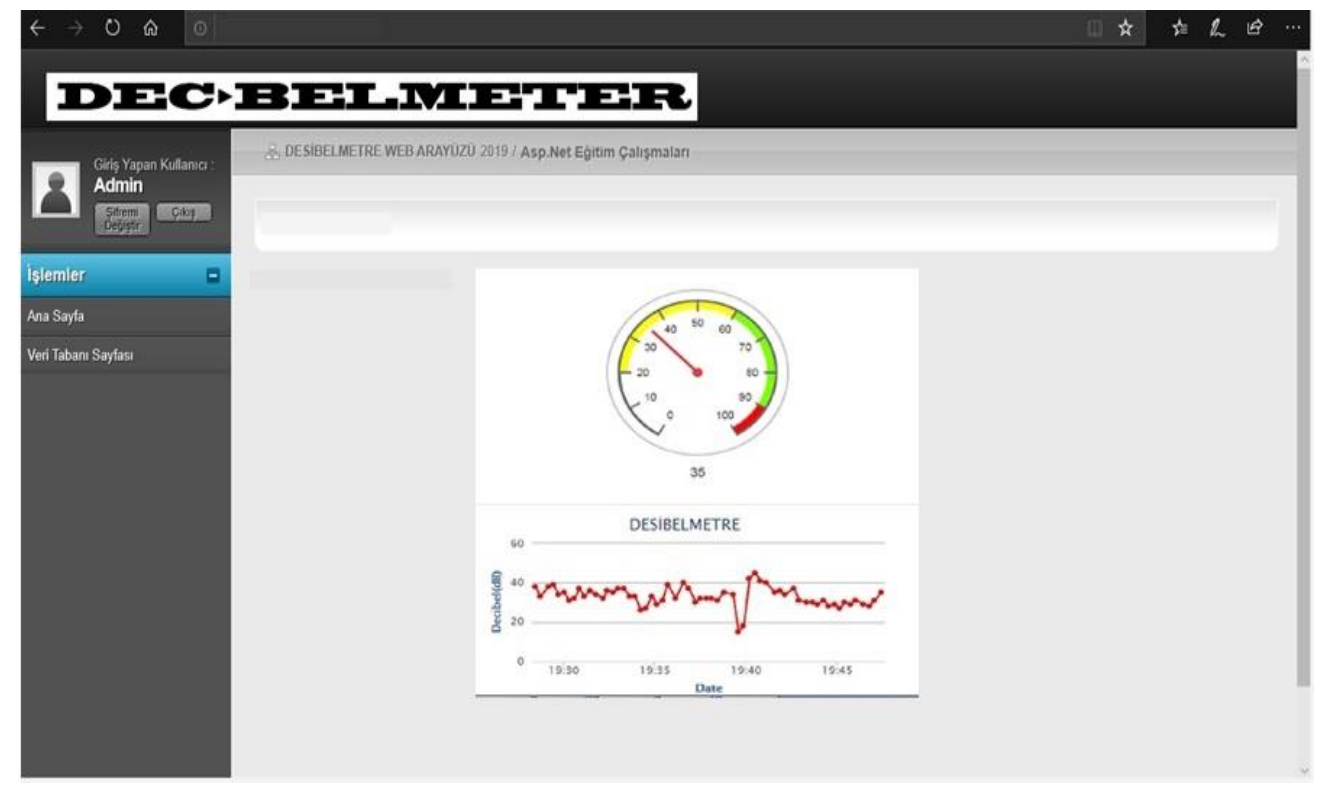

Figure 5. Web Interface Design Home Page

In short, the design of a web interface is a subject that requires separate efforts and attention. What needs to be done is to put forward a design that will address the code and purpose to be designed. Fig. 6 shows Web interface design database page.

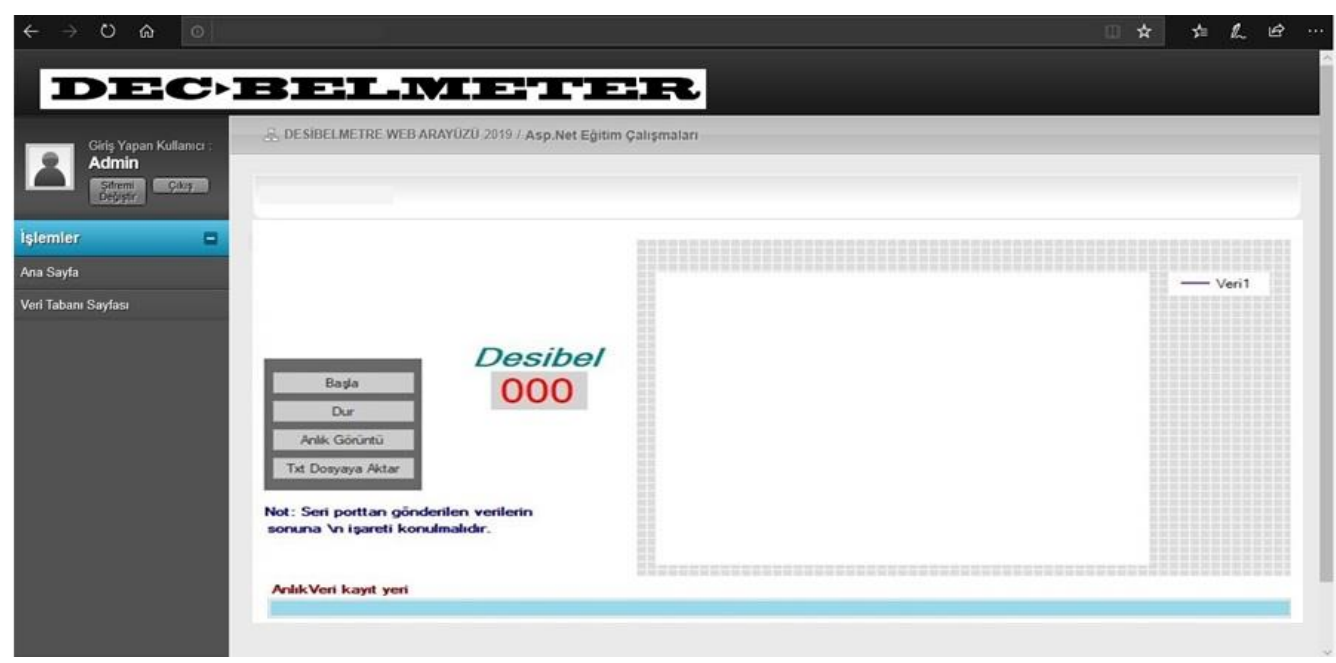

Figure 6. Web Interface Design Database Page 


\subsection{Programming the Web Interface}

The interface to be designed belongs to the web base on the Visual C\# platform ASP.NET it has been predicted to be made as a web application. The reason for this ASP.NET the interface is completely useful and the designer is completely independent and the design is able to be used at the highest level of visuality. In addition, depending on the operating performance of systems with a database and fast data exchange ASP.NET the interface should be preferred.

The designed interface consists of a home page and a database page. The snapshot values of the data taken from the master page and the graphical version of the data on the database page are shown as the data record table. This design should be done using the software Master Page structure on the code. The image, scripts, themes, and index files of the prepared web design should be added as items to the prepared solution. Using added design files ASP.NET software architecture is realized with. Fig. 7 shows Web interface programming.

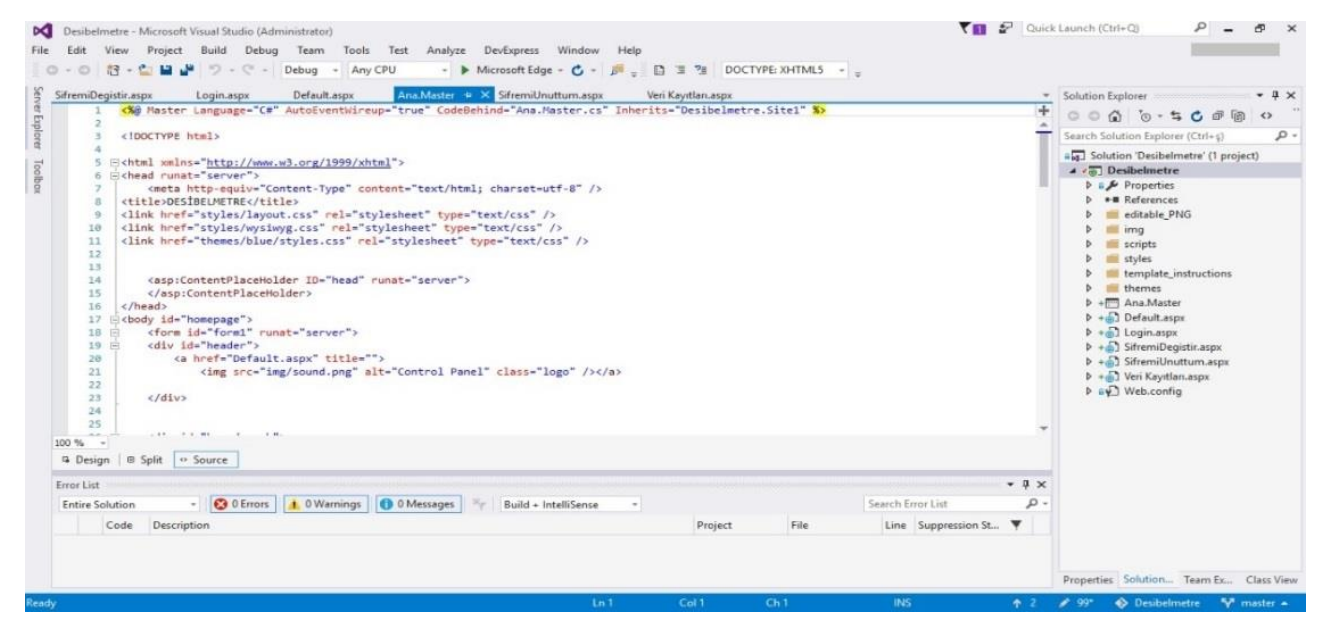

Figure 7. Web Interface Programming

The second stage of encoding is data recording. A database should be used to show which day and which time the data was taken. For this, the SQL structure must be used. This structure should be added to the web server and created as a database.

\subsection{Opening The Web Interface to Remote Access}

ASP.NET the base shows the values taken from the microcontroller in the interface, whose visuality is adjusted with the support of different design programs. However, this view only applies to the computer on which the interface is installed. In order to open the designed interface to access all clients, it is necessary to open the port specified over TCP IPS, where the computer is connected to the internet and the modem provides communication between them. The reason for this is to provide data transmission while at the same time creating the possibility to receive data. In this case, the computer used the data obtained from the microcontroller should be sent to the web address that provides hosting with the purchased ASP.NET. In this process, the purchased website server and any device to access 
this interface are set to client. Fig. 8 shows Web server where the web interface and data will be transferred.

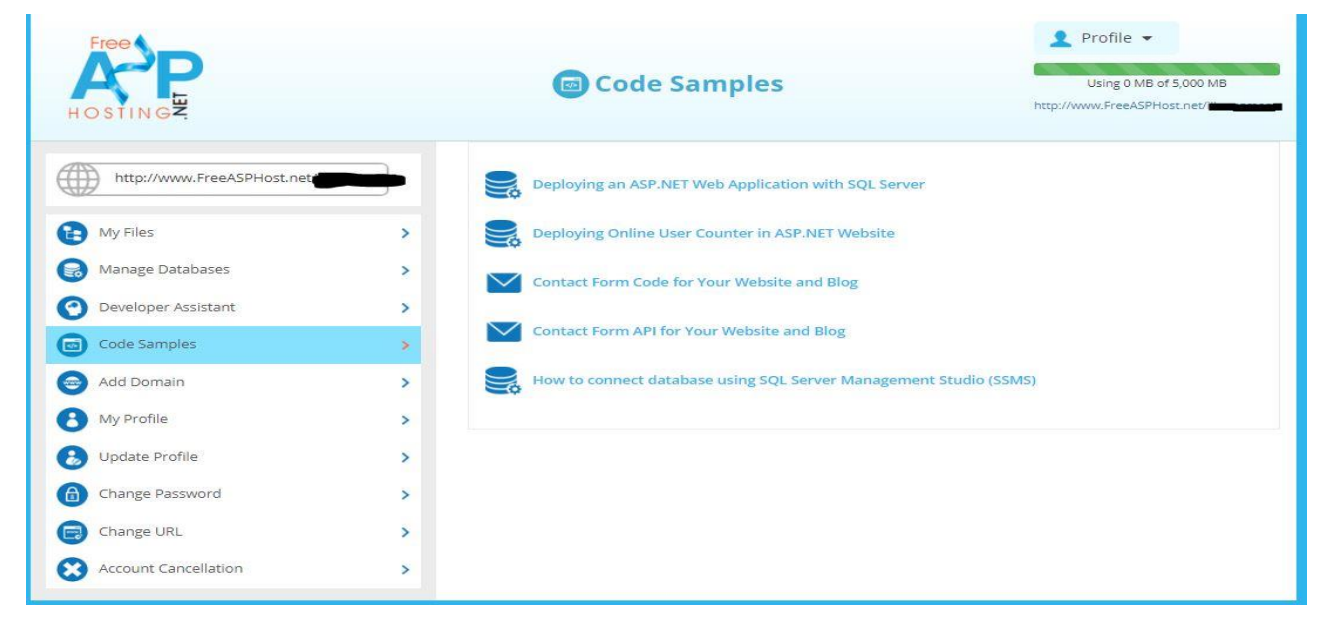

Figure 8. Web server where the web interface and data will be transferred

In order to perform this operation, it is necessary to first match the IP address that will be accessible to the microcontroller. Otherwise, the data received will not be able to be displayed in the designed interface. Every 15 seconds the received data must be sent to the website via The opened port. The reason the data is sent every 15 seconds is to prevent accretion in the database.

The process of opening the mapped IP address to clients is called Port Forwarding. This is done from the setting menu of the modem to which the server is connected to the internet. After the port routing process is done, the domain address that is rented from the hosting companies paying a certain fee must be defined as the server. Thus, both the cloud requirement and security vulnerability needed by the database will be eliminated. The purchased domain is personal and will be accessible to clients in the form of a web site and will be uploaded to this web site. ASP.NET the interface must be set to be continuously available for data retrieval by adding it to the panel page that the hosting company has opened. This process can be done by another methods.

Free and reliable platforms such as the developed tracking system, the ThingSpeak web interface and the pushingbox notification application are available. In this study, an original IoT-based noise monitoring system could be developed using open source software, modular and low cost components as an alternative to studies in the literatüre.

To summarize, first of all, the data from the sound sensor is processed and converted to dB values. Then, the converted data is transferred to the web server over the IP that has been Port Forwarding. Previously ASP.NET it is transferred to the web server whose interface has been added and paired with the microcontroller. This allows instant access to the data received over the internet. Fig. 9 shows Web interface design block diagram. 


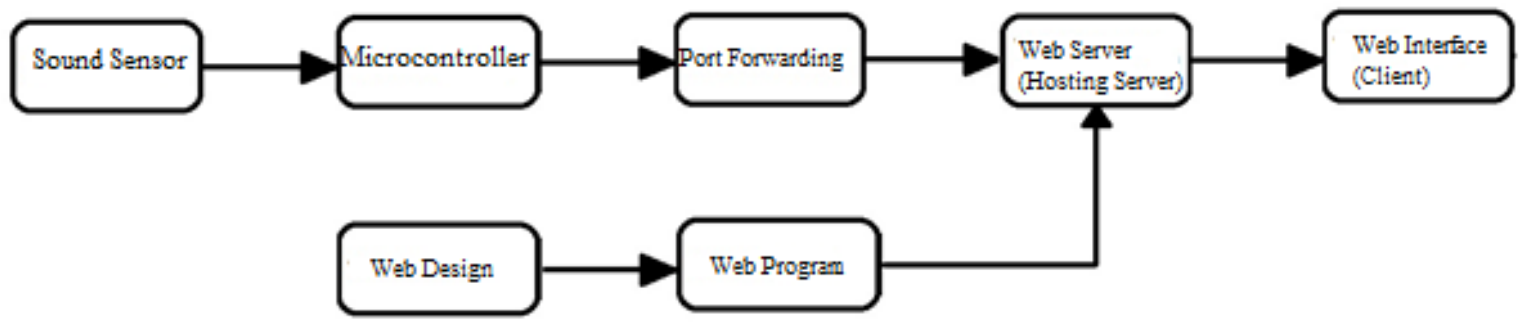

Figure 9. Web Interface Design Block Diagram

\section{Results}

In this study, environmental noise tracking system based on web of things was carried out. The study targeted unwanted and disturbing environmental noise problems at every point of life. Noise information can be monitored momentarily in environments where noise level is important, such as city centers, factories, hospitals, schools and entertainment areas. It is aimed to operate the system with a small margin of error, especially in environments where noise change is important. This margin of error can be minimized by replacing the appropriate sound sensor. With this work developed, access can be provided with a web interface created at any time from any place with a device with internet connection. It processes $\mathrm{ADC}$ data obtained from the sound sensor used in the designed noise meter and converts it to $\mathrm{dB}$ values. This converted data is transferred to the web server over the IP that has been Port Forwarding. Thus, instant access to the data is aimed. In later stages, the system may open an information interface or access to social media applications. Thus, when the noise value exceeds the upper limit or lower limit, an easier, practical solution can be achieved with the improvements included in the system.

As a result of this study, the changes generated by noise and the resulting intensity of people to take measures against it provided a great convenience. It has also been the basis for such studies to be carried out.

\section{References}

[1] Göçen, R. K., Sarı, E. M., Erman, A. T. (2016). Noisemap: An environmental noise monitoring sensor network. 24th Signal Processing and Communication Application Conference, SIU 2016.

[2] Çevre ve Orman Bakanlığı Çevre Yönetimi Genel Müdürlügü. (2011). Çevresel Gürültü Ölçüm ve Değerlendirme Kilavuzu. 3-85.

[3] Çevre ve Orman Bakanlığı. (2010). "Çevresel Gürültünün Değerlendirilmesi ve Yönetimi Yönetmeliği (2002/49/EC)", 1-13.

[4] Biçen, Y., Yaman, O. (2019). An Internet of Things (IoT) based Monitoring System for Oilimmersed Transformers. Balkan Journal of Electrical \& Computer Engineering, Vol. 7, No. 3, 226234.

[5] Gökrem, L., Bozuklu, M. (2016). Nesnelerin İnterneti: Yapılan Çalışmalar ve Ülkemizdeki Mevcut Durum. Gaziosmanpaşa Bilimsel Araştırma Dergisi, (13), 47-68. 
[6] Postalcıŏlu, S., Kurt, İ. (2018). Web Tabanlı Sicaklık Takip Sistemi. Kilis 7 Aralık Üniversitesi Fen ve Mühendislik Dergisi, Cilt 2, Say1 1, 56-63.

[7] Durgun, M. Web Nesneleri Temelli Ağ Mimarisi Tasarımı ve Uygulaması. Tokat Gaziosmanpaşa Üniversitesi Fen Bilimleri Enstitüsü, Doktora Tezi, Mart, 2019.

[8] Baytürk, M., Çetin, G. (2013). Gömülü Sunucu ile Tasarlanmış İnternet Tabanlı Sera Otomasyon Sistemi Uygulaması. Bilişim Teknolojileri Dergisi, 6(2), 53-57.

[9] Candan, Z. Gerçek Zamanlı Sistemlerin Web Üzerinde Kontrolünün Gerçekleştirilmesi. Bahçeşehir Üniversitesi, Fen Bilimleri Enstitüsü, Yüksek Lisans Tezi, 1-65, 2008.

[10] Dand11, E. ,Gültekin S. (2017). Web Service-based Automation System for Duration Scheduling and Remote Control of Traffic Signal Lights", International Conference on Computer Science and Engineering (UBMK), 948-953.

[11] Robotik Sistem, Arduino Nedir, 2019.

http://www.robotiksistem.com/.arduino_nedir_arduino_özellikleri.html.

[12] Seed Studio, Grove-Loudness Sensor, 2019. https:/wiki.seedstudio.com/GroveLoundness_Sensor/.

[13] Maker Robotistan, ESP8266 Dersleri 1: Tanıtım ve Güncelleme, 2019, https:/maker.robotistan.com/.esp8266-ile-iot-dersleri-1-esp8266-modulunu-guncelleme/. [Accessed:3-mart-2016]

[14] Güriş, S., Çağlayan, E., Güriş, B. EViews ile Temel Ekonometri. Der yayınları, 2017.

[15] Ergün, M. SSPS for Windows. Bilimsel Araştırma İstatistik Uygulamaları. Ocak yayınları, 1995.

[16] Orhunbilge, N. Uygulamalı Regresyon ve Korelasyon Analizi. Nobel Akademik Yayıncılık, 2017. 